medRxiv preprint doi: https://doi.org/10.1101/2020.10.22.20214882; this version posted October 26, 2020. The copyright holder for this preprint (which was not certified by peer review) is the author/funder, who has granted medRxiv a license to display the preprint in It is made available under a CC-BY-NC-ND 4.0 International license .

\title{
Does Obstructive sleep apnea increase the risk of Parkinson Disease? A systematic review
} and meta-analysis.

Tianming Zhao ${ }^{1, *}$, Kun Xuan ${ }^{1, *}$, Chenyu Sun ${ }^{2}$, Haixia Liu ${ }^{1}$, Xin Chen ${ }^{1}$, Yehuan Sun ${ }^{1,3}$

*Tianming Zhao and Kun Xuan contributed equally to this work.

${ }^{1}$ Department of Epidemiology and Health Statistics, School of Public Health, Anhui Medical University, No. 81 Meishan Road, Hefei 230032, Anhui, China

${ }^{2}$ AMITA Health Saint Joseph Hospital Chicago, 2900 N. Lake Shore Drive, Chicago, IL 60657, USA

${ }^{3}$ Center for Evidence-Based Practice, Anhui Medical University, No. 81 Meishan Road, Hefei, 230032, Anhui, China

Corresponding author: Yehuan Sun, Department of Epidemiology and Health Statistics, School of Public Health, Anhui Medical University, No. 81 Meishan Road, Hefei 230032, Anhui, China. E-mail: yhsun ahmu_edu@yeah.net. Telephone/Fax:86-551-65167725

\section{Abstract}

Objectives: The evidence of whether the obstructive sleep apnea (OSA) could increase the risk of Parkinson disease (PD) remains controversial. This meta-analysis was conducted in hopes of providing evidence of associations between the OSA and the risk of PD incidence.

Methods: Relevant studies published until 7 September, 2020 were retrieved from 6 databases. 6 studies were finally included based on our selection criteria. Hazard Ratios (HRs) and their 95\%CI of each study were collected to evaluate the relationship between obstructive sleep apnea and Parkinson disease risk. Subgroup analysis was performed based on gender and sample size.

Results: We find a positive association between obstructive sleep apnea and Parkinson disease risk $\left(\mathrm{HR}=1.64,95 \% \mathrm{CI}: 1.56-1.73, \mathrm{I}^{2}=23.8 \%\right)$. OSA patients have a higher risk of Parkinson disease than subjects without OSA, especially in male patients $\left(\mathrm{HR}=1.56,95 \% \mathrm{CI}: 1.30-1.87, \mathrm{I}^{2}=0.0 \%\right)$. Based on results of sensitivity analysis, our study results were quite stable.

Conclusions: Our results provided evidence of a modest positive association between obstructive sleep apnea and Parkinson disease. It is a certain degree of significance to improve our understanding of obstructive sleep apnea and take measures to prevent and treat it. Moreover, additional studies are recommended to explore this topic in more detail. This study was registered NOTE: This preprint reports new research that has not been certified by peer review and should not be used to guide clinical practice. 


\section{in PROSPERO (CRD42020207528).}

Keywords: Obstructive sleep apnea; Parkinson Disease; Cohort studies; Systematic review

\section{Introduction}

Characterized by partial or complete collapse of the upper airway during sleep several times, obstructive sleep apnea (OSA) could lead to reduced or absent airflow lasting for 10 seconds or even longer which are related to cortical arousal or a fall in blood oxygen saturation [1]. Patients with OSA may be unaware of their disease which could result in undiagnosed [2,3]. The threat of OSA to the health of general population cannot be ignored and the OSA could increase the risk of several diseases (hypertension, myocardial infarction, stroke, and diabetes, etc.) if not be treated properly [4-9]. Furthermore, two of the main pathophysiologic characteristics of OSA (intermittent hypoxia and sleep fragmentation) [10] are believed to contribute to poor health outcomes in OSA patients and the adverse effect on high oxygen-demanding organs may be more complicated [11]. Previous study has found that OSA patients showed brain abnormalities and metabolic deficits in multiple areas, and the tissue injury was presumed to be related to hypoxemia-induced processes [12]. Thus, clarifying the complications and potential health outcomes of OSA patients is of great importance both for healthcare and understanding of underlying mechanism.

Neurological conditions are the leading source of disability worldwide and as an important type of them, Parkinson's disease (PD) has been growing rapidly in prevalence, disability, and deaths these years $[13,14]$. Parkinson's disease is associated with neuronal injury and loss in the substantia nigra pars compacta, which is the major source of dopaminergic projections to basal ganglia; Parkinson's disease has could affect sensory, emotional, cognitive, and autonomic functions $[15,16]$. The prevalence of Parkinson's disease tends to increase with age [17] which is consistent with OSA [18]. These years, the potential association between sleep disorders and Parkinson disease has been widely concerned [19]. Previous studies indicated that the intermittent hypoxemia caused by OSA may increase the loss of dopaminergic neurons in brain areas related to PD, and OSA-related sleep fragmentation may also have adverse effects on the brain through decreasing neuronal excitability in regions including the locus coeruleus [20,21]. Besides, the Parkinson's disease comorbidity with obstructive sleep apnea (OSA) is another serious health 
problem and it was reported that the PD patients with OSA had higher morbidity of fatty liver disease and hypertension [22]. Although the prevalence of obstructive sleep apnea may be higher in Parkinson Disease patients compared to those without PD, some studies confirmed while others refuted the relationship of OSA with some risk factors and symptoms in patients with PD [23-25], which indicated that the potential correlation between OSA and PD is still not clear enough. Thus, our meta-analysis is needed to implement. In our study, we aimed to illuminate whether obstructive sleep apnea patients have an increased risk of Parkinson Disease incidence based on several published epidemiological studies.

\section{Methods}

We followed the Preferred reporting items for systematic reviews and meta-analysis (PRISMA) statement [26] to conduct our meta-analysis. Ethical approval was not applicable in this meta-analysis. The PICO question for our review is as follows: in human subjects, does having obstructive sleep apnea (compared to subjects without obstructive sleep apnea) increase the incidence of Parkinson's disease? (Participants: human subjects; Indicator/Exposure: obstructive sleep apnea; Comparison: no obstructive sleep apnea; Outcomes: Parkinson's disease) The protocol of this study was registered (PROSPERO ID: CRD42020207528; https://www.crd.york.ac.uk/prospero/display_record.php?RecordID=207528).

\section{Literature search}

The Literature search was performed through six databases including PubMed, ScienceDirect, Web of Science, China National Knowledge Infrastructure (CNKI), Wanfang database and Chinese VIP database up to 7 September, 2020 using the following search terms: (obstructive sleep apnea OR sleep apnea OR OSA OR obstructive sleep apnea syndrome OR OSAS) AND (Parkinson's disease OR Parkinson disease OR Parkinson OR PD). Relevant Chinese terms were applied to search the Chinese Databases. Only English and Chinese articles were included in this study.

\section{Eligibility criteria}

Eligible studies were selected by two independent authors (T.Z. and K.X.) based on such including criteria: (1) Observational studies had a focus on whether people with obstructive sleep apnea are more susceptible to Parkinson disease based on results that reported Risk Ratio/Hazard 
Ratio/Odds Ratio and the related Standard Error (SE) or 95\% confidence intervals (CI) or provided enough raw data to evaluate them; (2) Case-control studies or cohort studies; (3) Studies were published in Chinese or English. The exclusion criteria were as follows: (1) Reviews, case reports, editorials, meeting abstracts or other studies with interventional designs; (2) Studies lacked necessary information for our meta-analysis or used inappropriate statistical methods; (3) Studies with duplicate data published previously.

\section{Data extraction and quality assessment}

Two investigators (H.L. and X.C.) independently extracted the following information from every included article: first author's name, year of publication, study location, study design, age range of participants, sample size, total number of cases and controls (OSA patients or not), outcomes of interest (effect values and 95\%CI, prevalence of PD in OSA patients), exposure (OSA) and outcome (PD incidence) assessment, and adjusted covariates. Any disagreement will be resolved by discussion until an agreement is reached or by consulting a third author. We utilized the Newcastle-Ottawa Quality Assessment Scale (NOS) $[27,28]$ to assess the quality of included cohort studies and case-control studies. The NOS scale included 8 items, which could be stratified by three dimensions: selection, comparability, and outcome (for cohort studies) or exposure (for case-control studies) [29]. In our study, 7-9, 4-6 and 0-3 points represented high-quality, middle quality and low quality respectively [28].

\section{Statistical analysis}

For each included case-control and cohort studies evaluating the association between OSA and PD incidence, we obtained the HRs with 95\% CIs and transformed HR and their 95\% CI to their logarithms and standard errors (SEs) for further quantitative analysis. We pooled HRs with 95\% CIs to evaluate the potential link between OSA and Parkinson disease incidence. Besides, Cochran's $\chi^{2}$-based Q-statistic and $\mathrm{I}^{2}$ were also conducted to test the heterogeneity of included studies. In $\mathrm{Q}$ test, $\mathrm{p}$-value $<0.05$ was considered as a possibility of significant heterogeneity, and $\mathrm{I}^{2}$ statistics was used to estimate the degree of heterogeneity amongst the including studies; when $\mathrm{I}^{2}>50 \%$, we define it as high heterogeneity and the random effect model is used in overall and subgroup analysis to confirm the most conservative results [30,31]. If not, the fixed-effect model was used [30]. Subgroup analysis was performed separately based on gender and sample size. To 
test the stability of pooled results, sensitivity analysis was also performed through removing each eligible study sequentially. All statistical analyses will be performed using Stata (version 14.0) software (Stata Corporation, College Station, TX, USA).

\section{Results}

\section{Study selection and quality assessment}

Based on our search strategy, a total of 758 records were found. According to our inclusion and exclusion criteria, we finally selected 6 studies published from 2015 to 2020 (five retrospective cohort studies and one prospective cohort studies) which included more than 1.1 million individuals $[25,32-36]$. Among them, 5 retrospective cohort studies were utilized to perform meta-synthesis $[25,32,33,35,36]$. The details of selection are shown in Figure 1. Among these inclusive studies, one study was conducted in the USA, one study was conducted in Canada, and another four was conducted in Taiwan of China. The main characteristics of these studies are listed in Table 1. In the included prospective cohort study aiming to explore predictors of parkinsonism in idiopathic REM sleep behavior disorder (iRBD) [34], researchers analyzed several potential variables including sleep apnea (defined as apnea-hypopnea index cut-off $\geqslant 15 / \mathrm{h}$ ) among patients with iRBD. Considering the limited generalizability to general population, we didn't include this study into our meta-synthesis. Table 2 shows the results of quality assessment of included studies. All study scored between 6 and 7 points. Among them, two studies are middle-quality $[33,34]$ while rest of them are high-quality $[25,32,35,36]$.

\section{Meta-synthesis of results}

As shown in Figure 2.1, in our study, we found a positive relationship between the OSA and PD risk, the OSA patients have an increased risk of PD incidence based on the fixed effect model $\left(\mathrm{HR}=1.64,95 \% \mathrm{CI}: 1.56-1.73, \mathrm{I}^{2}=23.8 \%\right)$.

Subgroup analysis was conducted based on gender and sample size. In gender, male patients with OSA have an increased risk of PD incidence (HR=1.56, 95\%CI:1.30-1.87, $\mathrm{I}^{2}=0.0 \%$ ) (Figure 2.2). However, in female patients, the association was not significantly positive based on random effect model (HR=1.73, 95\%CI:0.99-3.05, $\left.\mathrm{I}^{2}=68.9 \%\right)$ (Figure 2.3). As for sample size, we omitted study with the largest sample [33] and synthesize other studies, we found positive association between the OSA and PD in studies with relatively small samples (HR=1.59, 95\%CI:1.36-1.85, 
$\left.I^{2}=40.4 \%\right)($ Figure 2.4$)$.

\section{Sensitivity and publication bias analysis}

We applied Egger's test and Begg's test to detect publication bias. Based on Begg's test $(\mathrm{p}=0.806)$ and Egger's test $(\mathrm{p}=0.728)$, the publication bias was acceptable and there was no evidence of distinct publication bias. According to the results of sensitivity analysis, the resulted was not changed when omitting each study sequentially, which indicated that our study results were quite stable.

\section{Discussion}

In our study, we found that obstructive sleep apnea patients have a higher risk of PD incidence (about 1.64 times higher than that in subjects without OSA) which synthesize studies covering areas from Asia and North America. According to subgroup analysis, when it comes to male patients, the correlation was still positive (the risk of PD in male OSA patients was 1.56 times higher than male subjects without OSA). Considering the high heterogeneity in female patients $\left(I^{2}=68.9 \%\right)$, we performed random effect model to evaluate the correlation in female patients. The risk of PD in female OSA patients was 1.73 times higher than female subjects without OSA though didn't significantly correlated. Besides, the results of subgroup analysis also indicated that gender may be the main source of heterogeneity. The potential reasons may as follow: firstly, limited by the sample size of female patients with or without OSA, our study results of female were not stable enough. Among individuals in subgroup analysis regarding to gender, female subject only accounted for approximately $27.8 \%$, which indicated that future studies are needed to explore the correlation in female patients based on a larger sample to get more stable results. Secondly, previous studies have demonstrated that OSA is more frequent in men than women with a male-to-female ratio 3:1 in the general population [37-39], which could affect the female OSA patients' enrollment and lead to the difference of sample size between gender.

As for the underlying mechanisms of PD risk among OSA patients, previous studies proposed that the main characteristics of OSA (intermittent hypoxia and sleep fragmentation) could lead to structural and functional changes in brain, which were closely related to a series of neurodegenerative disorders including PD [40,41]. To be specific, OSA-related intermittent 
hypoxemia has been proven to increase numerous products of oxidation, notably reactive oxygen, and nitrogen species, which could cause cognitive decline in the elderly, as well as in neurodegenerative diseases by injuries from oxidative stress $[40,42,43]$. It is also proposed that intermittent hypoxemia has been linked to dysfunction of the blood-brain barrier, which is critical to maintain brain homeostasis [40]. Besides, previous study has also implied that sleep fragmentation may contribute to the development of PD pathology through promotion of oxidative stress or impairment of the clearance of toxic proteins [44]. After all, OSA-related oxidative stress and inflammation have been believed to be involved in the pathophysiology of PD $[36,45,46]$. However, in the prospective cohort study of Postuma et al. [34], sleep apnea was not related to parkinsonism among subjects with $\mathrm{iRBD}(\mathrm{HR}=0.92,95 \% \mathrm{CI}$ : 0.7-1.2). Although the generalizability of subjects included in this study to general population was limited, the results of this work have also indicated that the underlying mechanism of PD risk among OSA patients is not clear enough and still needed to be explored by experimental studies in the future.

Compared to previous meta-analysis [47], our current meta-analysis has several strengths. First, our study further confirmed the association between OSA and PD incidence in a larger sample and covered a wider range of people including Asia and North America. We also used different methods to synthesize HRs in female patients. We performed random-effect model in order to get more conservative results and discussed the difference results of female subjects. Limited by the participants included in our study, the association was not stable enough and future studies still need to explore the potential correlations in female patients with larger sample size and high-quality study design. Besides, Sun et al. [47] only analyzed gender in their subgroup to explore the correlations between OSA and PD, in our study, we performed gender and sample size in our subgroup analysis in order to produce more convincing evidence.

There are several limitations in our meta-analysis. First, according to our study, the gender difference may be the main source of heterogeneity existing heterogeneity among the included studies, which makes our results needed to be improved and enriched in the future. Secondly, limited number of our included studies and the study design (retrospective cohort study) makes our study results needed to be further confirmed by more high-quality studies (prospective cohort) in the future. Thirdly, participants included in our studies merely comes from Taiwan of China and 
the USA, which limited the generalizability to general population in other countries.

\section{Conclusion}

In conclusion, our meta-analysis further confirmed that obstructive sleep apnea is significantly associated with an increased risk of Parkinson disease especially among male individuals. Future high-quality studies are needed to confirm our study results in female population and mechanisms of this potential relationship are needed to be explored as well.

\section{Conflict of interest}

The authors declare that there is no conflict of interest.

\section{References}

1. Gottlieb DJ, Punjabi NM. (2020) Diagnosis and Management of Obstructive Sleep Apnea: A Review. JAMA 323(14):1389-1400.

2. Veasey SC, Rosen IM. (2019) Obstructive Sleep Apnea in Adults. N Engl J Med. 380(15):1442-1449.

3. Goodchild TT, Lefer DJ. (2020) Obstructive Sleep Apnea: The Not-So-Silent Killer. Circ Res. 126(2):229-231

4. Franklin KA, Lindberg E. (2015) Obstructive sleep apnea is a common disorder in the population-a review on the epidemiology of sleep apnea. J Thorac Dis. 7(8):1311-1322.

5. Morsy NE, Farrag NS, Zaki NFW, et al. (2019) Obstructive sleep apnea: personal, societal, public health, and legal implications. Rev Environ Health. 34(2):153-169.

6. Durán-Cantolla J, Aizpuru F, Martínez-Null C, Barbé-Illa F. (2009) Obstructive sleep apnea/hypopnea and systemic hypertension. Sleep Med Rev. 13(5):323-331.

7. Marin JM, Carrizo SJ, Vicente E, Agusti AG. (2005) Long-term cardiovascular outcomes in men with obstructive sleep apnoea-hypopnoea with or without treatment with continuous positive airway pressure: an observational study. Lancet. 365(9464):1046-1053.

8. Yaggi HK, Concato J, Kernan WN, Lichtman JH, Brass LM, Mohsenin V. (2005) Obstructive sleep apnea as a risk factor for stroke and death. N Engl J Med. 353(19):2034-2041.

9. Morgenstern M, Wang J, Beatty N, Batemarco T, Sica AL, Greenberg H. (2014) Obstructive sleep apnea: an unexpected cause of insulin resistance and diabetes. Endocrinol Metab Clin North Am. 43(1):187-204. 
medRxiv preprint doi: https://doi.org/10.1101/2020.10.22.20214882; this version posted October 26, 2020. The copyright holder for this preprint (which was not certified by peer review) is the author/funder, who has granted medRxiv a license to display the preprint in It is made available under a CC-BY-NC-ND 4.0 International license .

10. Martínez-García MÁ, Campos-Rodriguez F, Barbé F. (2016) Cancer and OSA: Current Evidence From Human Studies. Chest. 150(2):451-463.

11. Beaudin AE, Hartmann SE, Pun M, Poulin MJ. (2017) Human cerebral blood flow control during hypoxia: focus on chronic pulmonary obstructive disease and obstructive sleep apnea. $\mathbf{J}$ Appl Physiol (1985). 123(5):1350-1361.

12. Tummala S, Palomares J, Kang DW, et al. (2016) Global and Regional Brain Non-Gaussian Diffusion Changes in Newly Diagnosed Patients with Obstructive Sleep Apnea. Sleep. 39(1):51-57.

13. Armstrong MJ, Okun MS. (2020) Diagnosis and Treatment of Parkinson Disease: A Review. JAMA. 323(6):548-560.

14. GBD 2016 Parkinson's Disease Collaborators. Global, regional, and national burden of Parkinson's disease, 1990-2016: a systematic analysis for the Global Burden of Disease Study 2016. Lancet Neurol. 2018;17(11):939-953.

15. Homayoun H. (2018) Parkinson Disease. Ann Intern Med. 169(5):ITC33-ITC48.

16. Dickson DW, Braak B, Duda JE, et al. (2009) Neuropathological assessment of Parkinson's disease: refining the diagnostic criteria. Lancet. 8(12): 1150-1157.

17. Pringsheim T, Jette N, Frolkis A, Steeves TD. (2014) The prevalence of Parkinson's disease: a systematic review and meta-analysis. Mov Disord. 29(13):1583-1590.

18. Fietze I, Laharnar N, Obst A, et al. (2019) Prevalence and association analysis of obstructive sleep apnea with gender and age differences - Results of SHIP-Trend. J Sleep Res. 28(5):e12770.

19. Gan-Or Z, Alcalay RN, Rouleau GA, Postuma RB. (2018) Sleep disorders and Parkinson disease; lessons from genetics. Sleep Med Rev. 41:101-112.

20. Meng L, Benedetti A, Lafontaine AL, et al. (2020) Obstructive sleep apnea, CPAP therapy and Parkinson's disease motor function: A longitudinal study. Parkinsonism Relat Disord. 70:45-50.

21. Li Y, Panossian LA, Zhang J, et al. (2014) Effects of chronic sleep fragmentation on wake-active neurons and the hypercapnic arousal response. Sleep. 37(1):51-64.

22. Shen Y, Shen Y, Dong ZF, Pan PL, Shi HC, Liu CF. (2020) Obstructive sleep apnea in Parkinson's disease: a study in 239 Chinese patients. Sleep Med. 67:237-243.

23. Sobreira-Neto MA, Pena-Pereira MA, Sobreira EST, et al. (2019) Obstructive sleep apnea and 
medRxiv preprint doi: https://doi.org/10.1101/2020.10.22.20214882; this version posted October 26, 2020. The copyright holder for this preprint (which was not certified by peer review) is the author/funder, who has granted medRxiv a license to display the preprint in It is made available under a CC-BY-NC-ND 4.0 International license .

Parkinson's disease: characteristics and associated factors. Arq Neuropsiquiatr. 77(9):609-616.

24. Trotti LM, Bliwise DL. (2010) No increased risk of obstructive sleep apnea in Parkinson's disease. Mov Disord. 25(13):2246-2249.

25. Chen JC, Tsai TY, Li CY, Hwang JH. (2015) Obstructive sleep apnea and risk of Parkinson's disease: a population-based cohort study. J Sleep Res. 24(4):432-437.

26. Moher D, Liberati A, Tetzlaff J, Altman DG; PRISMA Group. (2009) Preferred reporting items for systematic reviews and meta-analyses: the PRISMA statement. PLoS Med. 6(7):e1000097.

27. Wells GA, Shea B, O'Connell D, Peterson J, Welch V, Losos M, et al. (2014) The Newcastle-Ottawa Scale (NOS) for assessing the quality of nonrandomized studies in meta-analyses. Ottawa, Canada: Ottawa Health Research Institute.

28. Li Z, Huang W, Wang X, Zhang Y. (2018) The relationship between lower urinary tract symptoms and irritable bowel syndrome: a meta-analysis of cross-sectional studies. Minerva Urol Nefrol. 70(4):386-392.

29. Stang A. (2010) Critical evaluation of the Newcastle-Ottawa scale for the assessment of the quality of nonrandomized studies in meta-analyses. Eur J Epidemiol. 25(9):603-605.

30. Shi T, Min M, Sun C, Zhang Y, Liang M, Sun Y. (2018) Periodontal disease and susceptibility to breast cancer: A meta-analysis of observational studies. J Clin Periodontol. 45(9):1025-1033.

31. Higgins JP, Thompson SG, Deeks JJ, Altman DG. (2003) Measuring inconsistency in meta-analyses. BMJ. 327(7414):557-560.

32. Chou PS, Lai CL, Chou YH, Chang WP. (2017) Sleep apnea and the subsequent risk of Parkinson's disease: a 3-year nationwide population-based study. Neuropsychiatr Dis Treat. 13:959-965.

33. Kummer BR, Diaz I, Wu X, et al. (2019) Associations between cerebrovascular risk factors and parkinson disease. Ann Neurol. 86(4):572-581.

34. Postuma RB, Iranzo A, Hu M, et al. (2019) Risk and predictors of dementia and parkinsonism in idiopathic REM sleep behaviour disorder: a multicentre study. Brain. 142(3):744-759.

35. Sheu JJ, Lee HC, Lin HC, Kao LT, Chung SD. (2015) A 5-Year Follow-up Study on the Relationship between Obstructive Sleep Apnea and Parkinson Disease. J Clin Sleep Med. 11(12):1403-1408. 
medRxiv preprint doi: https://doi.org/10.1101/2020.10.22.20214882; this version posted October 26, 2020. The copyright holder for this preprint (which was not certified by peer review) is the author/funder, who has granted medRxiv a license to display the preprint in It is made available under a CC-BY-NC-ND 4.0 International license .

36. Yeh NC, Tien KJ, Yang CM, Wang JJ, Weng SF. (2016) Increased Risk of Parkinson's Disease in Patients With Obstructive Sleep Apnea: A Population-Based, Propensity Score-Matched, Longitudinal Follow-Up Study. Medicine (Baltimore). 95(2):e2293.

37. Schiza SE, Bouloukaki I. (2020) Does gender matter: sex-specific aspects of symptoms, outcome, and therapy of obstructive sleep apnea. Curr Opin Pulm Med. 26(6):642-649.

38. Young T, Palta M, Dempsey J, Skatrud J, Weber S, Badr S. (1993) The occurrence of sleep-disordered breathing among middle-aged adults. N Engl J Med. 328(17):1230-1235.

39. Lin CM, Davidson TM, Ancoli-Israel S. (2008) Gender differences in obstructive sleep apnea and treatment implications. Sleep Med Rev. 12(6):481-496.

40. Lajoie AC, Lafontaine AL, Kimoff RJ, Kaminska M. (2020) Obstructive Sleep Apnea in Neurodegenerative Disorders: Current Evidence in Support of Benefit from Sleep Apnea Treatment. J Clin Med. 9(2):297.

41. Gosselin N, Baril AA, Osorio RS, Kaminska M, Carrier J. (2019) Obstructive Sleep Apnea and the Risk of Cognitive Decline in Older Adults. Am J Respir Crit Care Med. 199(2):142-148.

42. Lavie L, Lavie P. (2009) Molecular mechanisms of cardiovascular disease in OSAHS: the oxidative stress link. Eur Respir J. 33(6):1467-1484.

43. Beal MF. (1995) Aging, energy, and oxidative stress in neurodegenerative diseases. Ann Neurol. 38(3):357-366.

44. Sohail S, Yu L, Schneider JA, Bennett DA, Buchman AS, Lim ASP. (2017) Sleep fragmentation and Parkinson's disease pathology in older adults without Parkinson's disease. Mov Disord. 32(12):1729-1737.

45. Taylor JM, Main BS, Crack PJ. (2013) Neuroinflammation and oxidative stress: co-conspirators in the pathology of Parkinson's disease. Neurochem Int. 62(5):803-819.

46. Olanow CW. (2007) The pathogenesis of cell death in Parkinson's disease--2007. Mov Disord. 22 (Suppl 17):S335-S342.

47. Sun AP, Liu N, Zhang YS, Zhao HY, Liu XL. (2020) The relationship between obstructive sleep apnea and Parkinson's disease: a systematic review and meta-analysis. Neurol Sci. 41(5):1153-1162. 


Records identified through
database searching $(n=758)$
230 from PubMed
107 from ScienceDirect
365 from Web of Science
20 from CNKI
5 from VIP Database

Records after duplicates removed

Additional records identified through other sources

$$
(n=0)
$$

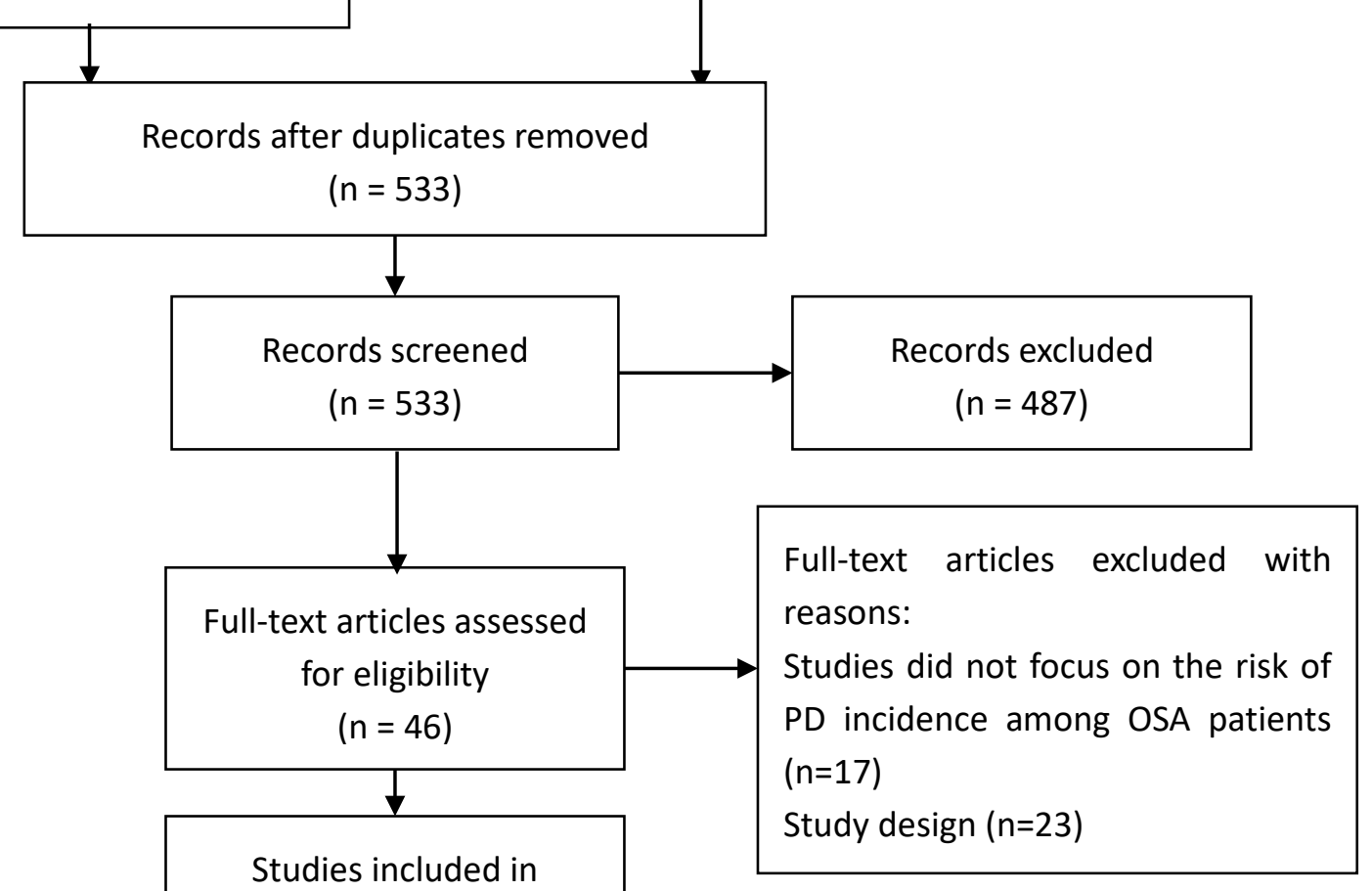

qualitative synthesis

$$
(n=6)
$$

Studies included in

quantitative synthesis

(meta-analysis)

$$
(n=5)
$$

Figure 1. Flow chart of selecting eligible studies. 
medRxiv preprint doi: https://doi.org/10.1101/2020.10.22.20214882; this version posted October 26, 2020. The copyright holder for this preprint (which was not certified by peer review) is the author/funder, who has granted medRxiv a license to display the preprint in It is made available under a CC-BY-NC-ND 4.0 International license

2.1

Study

$\operatorname{HR}(95 \% \mathrm{Cl}) \quad$ Weight

ID

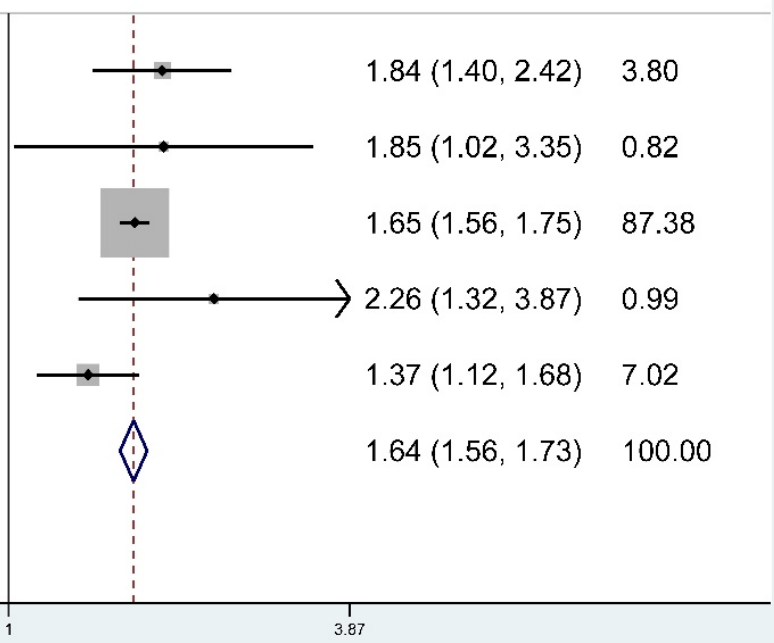

2.2

Study

ID

Chen (2015)

Chou (2017)

Sheu (2015)

Yeh (2016)

Overall $(\mathrm{I}$-squared $=0.0 \%, p=0.715)$
$\%$

HR $(95 \% \mathrm{Cl}) \quad$ Weight

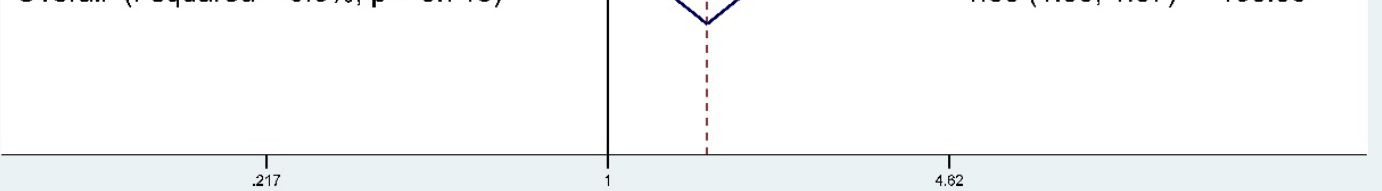


medRxiv preprint doi: https://doi.org/10.1101/2020.10.22.20214882; this version posted October 26, 2020. The copyright holder for this preprint (which was not certified by peer review) is the author/funder, who has granted medRxiv a license to display the preprint in It is made available under a CC-BY-NC-ND 4.0 International license .

2.3

Study

ID
$\mathrm{HR}(95 \% \mathrm{Cl}) \quad$ Weight

\section{Chen (2015)}

Chou (2017)

Sheu (2015)

Yeh (2016)

Overall (I-squared $=68.9 \%, p=0.022)$

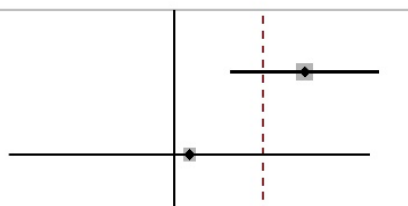

$2.25(1.42,3.57) \quad 31.19$

$1.10(0.36,3.38) \quad 15.40$

$3.54(1.50,8.35) \quad 20.63$

$1.07(0.72,1.60) \quad 32.79$

$1.73(0.99,3.05) \quad 100.00$

NOTE: Weights are from random effects analysis

2.4

Study

ID

\section{Chen (2015)}

Chou (2017)

Sheu (2015)

Yeh (2016)

Overall $(I$-squared $=40.4 \%, p=0.169)$
$\mathrm{HR}(95 \% \mathrm{Cl}) \quad$ Weight

Figure 2. Forest plots of hazard ratio of PD risk of OSA patients; 2.1, the overall results of association between OSA and PD incidence; 2.2, the association between OSA and PD incidence among male patients; 2.3, association between OSA and PD incidence in female patients; 2.4 the association between OSA and PD incidence in studies with relatively small samples. 
Table 1. Characteristics of included studies

\begin{tabular}{|c|c|c|c|c|c|c|c|c|}
\hline $\begin{array}{l}\text { First } \\
\text { author }\end{array}$ & $\begin{array}{l}\text { Published } \\
\text { year }\end{array}$ & $\begin{array}{l}\text { Study } \\
\text { location }\end{array}$ & Study design & $\begin{array}{l}\text { Mean age/age } \\
\text { range }\end{array}$ & $\begin{array}{l}\text { Sample } \\
\text { size }\end{array}$ & $\begin{array}{l}\text { OSA } \\
\text { ascertainment }\end{array}$ & $\begin{array}{l}\text { PD } \\
\text { ascertainment }\end{array}$ & $\begin{array}{c}\text { Effect } \\
\text { value }(95 \% \mathrm{CI})\end{array}$ \\
\hline Chen [25] & 2015 & Taiwan & $\begin{array}{l}\text { Retrospective cohort } \\
\text { study }\end{array}$ & 45.6 & 29,133 & $\begin{array}{l}\text { ICD-9-CM codes } \\
780.51,780.53 \text { or } \\
780.57\end{array}$ & NA & $1.84(1.40-2.43)^{\mathrm{a}}$ \\
\hline Chou [32] & 2017 & Taiwan & $\begin{array}{l}\text { Retrospective cohort } \\
\text { study }\end{array}$ & $\geq 40$ & 11,664 & $\begin{array}{l}\text { ICD-9-CM codes } \\
780.51,780.53 \text {, } \\
780.57 \text { or } 327.23\end{array}$ & $\begin{array}{l}\text { Receiving any } \\
\text { outpatient or } \\
\text { inpatient care for } \\
\text { PD (ICD-9-CM } \\
332 \text { ) }\end{array}$ & $1.85(1.02-3.35)^{\mathrm{b}}$ \\
\hline Kummer [33] & 2019 & USA & $\begin{array}{l}\text { Retrospective cohort } \\
\text { study }\end{array}$ & 75.9 & $1,035,536$ & NA & $\begin{array}{l}\text { Separate } \\
\text { outpatient claims } \\
\text { for idiopathic PD } \\
\text { (ICD-9-CM 332) }\end{array}$ & $1.65(1.56-1.75)^{\mathrm{c}}$ \\
\hline Postuma [34] & 2019 & Canada & Prospective cohort study & 66.3 & 1,280 & $\mathrm{AHI} \geq 15$ & $\begin{array}{l}\text { Neurologist } \\
\text { testing }\end{array}$ & $0.92(0.70-1.23)^{\mathrm{d}}$ \\
\hline Sheu [35] & 2015 & Taiwan & $\begin{array}{l}\text { Retrospective cohort } \\
\text { study }\end{array}$ & 46.5 & 9,192 & $\begin{array}{l}\text { ICD-9-CM codes } \\
327.23,780.51 \text {, } \\
780.53 \text { or } 780.57 \\
\text { and PSG for } \\
\text { confirmation }\end{array}$ & NA & $2.26(1.32-3.88)^{\mathrm{e}}$ \\
\hline
\end{tabular}




\begin{tabular}{|c|c|c|c|c|c|c|c|c|}
\hline Yeh [36] & 2016 & Taiwan & $\begin{array}{l}\text { Retrospective cohort } \\
\text { study }\end{array}$ & NA & 33,460 & $\begin{array}{l}\text { Patients met the } \\
\text { diagnostic criteria } \\
\text { for that disease in } \\
\text { at least } 3 \text { outpatient } \\
\text { service claims with } \\
\text { codes for OSA } \\
\text { (ICD-9-CM code } \\
780.51,780.53 \text {, } \\
780.57 \text { or } 327.23 \text { ) } \\
\text { at the department } \\
\text { or division of Chest } \\
\text { Medicine at any } \\
\text { hospital or local } \\
\text { medical clinic }\end{array}$ & $\begin{array}{l}\text { Patients met the } \\
\text { relevant } \\
\text { diagnostic } \\
\text { criteria for that } \\
\text { disease in at least } \\
3 \text { outpatient } \\
\text { service claims } \\
\text { with codes for } \\
\text { PD (ICD-9-CM } \\
\text { code } 332 \text { ) }\end{array}$ & $1.37(1.12-1.68)^{\mathrm{f}}$ \\
\hline
\end{tabular}

Note: CI: confidence interval; OSA, obstructive sleep apnea; PD, Parkinson Disease; NA: not available; AHI: apnea-hypopnea index.

a, hazard ratio (HR), adjusted factors: age, sex, urbanization level, income, and comorbidity;

b, hazard ratio (HR), adjusted factors: sex, age, urbanization level, geographic region, monthly income, hypertension, hyperlipidemia, diabetes mellitus, asthma, COPD, and head injury;

c, hazard ratio (HR), adjusted factors: age, sex, race/ethnicity, and baseline Charlson comorbidities;

d, hazard ratio (HR), adjusted factors: adjusted for age, sex and recruiting center;

e, hazard ratio (HR) stratified by sex, age group and year of index ambulatory care visit and adjusted for patients' geographical location, urbanization level, and monthly income;

f, hazard ratio (HR), adjusted factors: age, sex, diabetes, hypertension, coronary artery disease, stroke, hyperlipidemia, chronic kidney disease, and gout. 
Table 2. Newcastle - Ottawa quality assessment scale (cohort study)

\begin{tabular}{|c|c|c|c|c|c|c|c|c|c|c|}
\hline \multirow{2}{*}{ Study } & \multirow{2}{*}{ Year } & \multicolumn{4}{|c|}{ Selection } & \multirow{2}{*}{$\frac{\text { Comparability }}{\mathrm{E}}$} & \multicolumn{3}{|c|}{ Outcome } & \multirow[t]{2}{*}{ Total } \\
\hline & & $\mathrm{A}$ & $\mathrm{B}$ & $\mathrm{C}$ & $\mathrm{D}$ & & $\mathrm{F}$ & $\mathrm{G}$ & $\mathrm{H}$ & \\
\hline Chen [25] & 2015 & 1 & 1 & 1 & 1 & 1 & 1 & 1 & 0 & 7 \\
\hline Chou [32] & 2017 & 1 & 1 & 1 & 1 & 1 & 1 & 1 & 0 & 7 \\
\hline Kummer [33] & 2019 & 0 & 1 & 1 & 1 & 1 & 1 & 1 & 0 & 6 \\
\hline Postuma [34] & 2019 & 0 & 1 & 1 & 1 & 1 & 1 & 1 & 0 & 6 \\
\hline Sheu [35] & 2015 & 1 & 1 & 1 & 1 & 1 & 1 & 1 & 0 & 7 \\
\hline Yeh [36] & 2015 & 1 & 1 & 1 & 1 & 1 & 1 & 1 & 0 & 7 \\
\hline
\end{tabular}

A: Representativeness of the exposed cohort; B: Selection of the nonexposed cohort; C: Ascertainment of exposure; D:

Demonstration that outcome of interest was not present at start of study; E: Comparability of cohorts on the basis of the design or analysis; F: Assessment of outcome; G: Was follow-up long enough for outcomes to occur; H: Adequacy of follow up of cohorts 